\title{
A socio-technical analysis of low-carbon transitions: introducing the multi-level perspective into transport studies
}

\author{
Frank W. Geels * \\ SPRU, Science and Technology Policy Research, Freeman Centre, University of Sussex, Brighton BN1 9QE, United Kingdom
}

\section{A R T I C L E I N F O}

\section{Keywords:}

Socio-technical transitions

Transport systems

Low-carbon

Multi-level perspective

\begin{abstract}
A B S T R A C T
Climate change and deep cuts in $\mathrm{CO}_{2}$ emissions require transitions to new kinds of transport systems. To understand the dynamics of these transitions, this paper introduces a socio-technical approach which goes beyond technology fix or behaviour change. Systemic transitions entail co-evolution and multidimensional interactions between industry, technology, markets, policy, culture and civil society. A multi-level perspective (MLP) is presented as a heuristic framework to analyze these interactions. The paper aims to introduce the MLP into transport studies and to show its usefulness through an application to the auto-mobility system in the United Kingdom and the Netherlands. This application aims to assess the drivers, barriers and possible pathways for low-carbon transitions.
\end{abstract}

(c) 2012 Elsevier Ltd. All rights reserved.

\section{Introduction}

Environmental problems such as climate change present formidable challenges for transport, which is one of the few sectors where $\mathrm{CO}_{2}$ emissions continue to rise. Reducing carbon emissions by $80 \%$ can only be realised by deep-structural changes in transport systems. The socio-technical approach to transitions conceptualises transport systems as a configuration of elements that include technology, policy, markets, consumer practices, infrastructure, cultural meaning and scientific knowledge (Kemp et al., 1998; Elzen et al., 2004; Geels, 2004; Smith et al., 2005; Verbong and Geels, 2007; Smith, 2007). As a shorthand, these systems are labelled 'socio-technical' systems and major shifts are indicated as socio-technical transitions. The elements in socio-technical systems are maintained, reproduced and changed by various actor groups (e.g. firms and industries, policy makers and politicians, consumers, civil society, engineers and researchers). Transitions are seen as co-evolutionary processes, which take decades to unfold and involve many actors and social groups.

The socio-technical approach to transitions is broader than other approaches to sustainable development. To bring out the differences, I give a stylised characterisation of the most prominent alternative approaches.

(1) Neo-classical economists view environmental problems as negative externalities resulting from market failures. The government can help internalise external costs by changing incentives and frame conditions (e.g. taxes, emissions trad-

\footnotetext{
* Tel.: +44 (0)1273678 171 .

E-mail address: f.w.geels@sussex.ac.uk
}

ing), but should then let private initiative do the real work. If the prices are right, private actors (firms and consumers) will find optimal (profit or utility maximising or cost-effective) solutions, which are supposed to lead to socially more desirable outcome. This framing often dominates policy discussions (e.g. Stern, 2006).

(2) Psychologists focus on the attitude and behaviour of individuals whose aggregate choices are assumed to produce societal outcomes (e.g. Kaiser et al., 1999). Assuming that behaviour change is caused by changes in attitudes, they make policy recommendations that highlight information provision and education campaigns.

(3) Deep ecologists relate environmental problems to the failures of modernism, capitalism and anthropocentrism (e.g. Næss, 1973). They therefore advocate cultural change towards eco-centrist approaches, which include 'green values' and new ideologies (e.g. localism, self-sufficiency).

(4) Engineers and industrial ecologists see environmental problems arising from inefficient and polluting production processes. Building on a strong belief that science and technology can deliver solutions, they advocate clean technology, eco-efficiency, dematerialisation, and the closing of material loops (e.g. Huber, 2000).

(5) Political scientists (e.g. Newell, 2008) study the development and struggles over formal goals and targets as embedded international treaties (e.g. Kyoto, Millennium Development Goals). These goals are subsequently translated into regulations and policy programs, which are then implemented and controlled by bureaucrats and backed up by sanctions. Environmental management standards (e.g. ISO14001), performance reporting, and environmental impact assessments may be part of this process. 
Each of the above approaches focuses on a limited set of dimensions of (un)sustainability. The socio-technical approach to transitions instead highlights co-evolution and multi-dimensional interactions between industry, technology, markets, policy, culture and civil society. This paper aims to introduce the socio-technical approach into transport studies, which appears to be dominated by approaches 1 and 4, and, to a lesser extent, approach 2 . In an extensive review of transport studies research on climate change mitigation, Schwanen et al. (2011, p. 1002) conclude: "There is a strong emphasis on mitigation via technology, economic instruments and infrastructure provision, and to a lesser degree on reconfigurations of travellers' psyche through information campaigns and social marketing (...). Insights from engineering, (neo-classical) economics and to a lesser degree psychology prevail and most research is predicated on the use of quantitative methods embedded in positivist epistemological frameworks." Schwanen et al. (2011) therefore suggest that transport studies may benefit from using "insights, concepts and methods from other disciplines, and particularly the social sciences". To address challenges such as climate change, peak oil and energy security, the editorial to a special issue on 'alternative travel futures' also highlights "the continuing need for transport research to embrace multiple perspectives to understand the complexities of modern mobility" (Pangbourne and Anable, 2011, p. 1535). The editors also suggest that "transport academics need to begin to apply this creativity and interdisciplinarity within a broader systems perspective" (p. 1536).

While some transport scholars have started to explore this research direction (e.g. Urry, 2004, 2011; Banister, 2008; Sperling and Gordon, 2009; Dennis and Urry, 2009), this paper aims to further develop it. Understanding large-scale transitions to new transport systems requires analytical frameworks that encompass multiple approaches in ways that addresses interactions between them. The multi-level perspective (MLP), which will be discussed in this paper, is one such framework. The MLP was developed in the field of innovation studies, drawing on insights from evolutionary economics (technological trajectories, regimes, niches, speciation), sociology of technology (innovations are socially constructed through interactions between engineers, firms, consumers, policy makers) and neo-institutional theory (actors are constrained by shared beliefs, norms and regulations). The MLP provides a way of addressing the core analytical puzzle of transitions, namely stability and change. On the one hand, existing systems are characterised by stability, lock-in, and path dependence, which give rise to incremental change along predictable trajectories. On the other hand, radical alternatives are being proposed, developed and tried by pioneers, entrepreneurs, social movements and other relative outsiders (to the existing regime). These alternatives typically face an uphill struggle against existing systems, because they are more expensive (since they have not yet benefited from economies of scale and learning curves), require changes in user practices, face a mismatch with existing regulations, or lack an appropriate infrastructure. The core puzzle in transitions thus centres around (dynamic) stability and (radical) change, and how the interactions are played out on multiple dimensions. The MLP provides a way of investigating these issues.

The usefulness of the MLP has been illustrated with historical case studies of transitions in land transport (Geels, 2005), shipping (Geels, 2002), cargo handling (Van Driel and Schot, 2005), sanitation, water supply, aviation, highway systems, and industrial production, and contemporary transitions in electricity systems (Verbong and Geels, 2007), mobility (Nykvist and Whitmarsh, 2008) organic food and sustainable housing (Smith, 2007). The aim of this paper is to introduce the MLP into transport studies, and illustrate its usefulness with an application to auto-mobility in the United Kingdom and the Netherlands (based on empirical chapters from Geels et al., 2012).
The paper is structured as follows. Section 2 introduces the MLP. Section 3 applies the MLP to the auto-mobility system, analysing the drivers, barriers and possible pathways for low-carbon transitions. This empirical application has the character of an interpretive assessment with tradeoffs between breadth and depth. While the assessment is broad (to address the various dimensions of transport systems and change initiatives), many real-world nuances and complexities are backgrounded in favour of larger patterns. Section 4 draws conclusions about low-carbon transitions and makes some evaluative remarks.

\section{The multi-level perspective on transitions}

The basic premise of the multi-level perspective (MLP) is that transitions are non-linear processes that result from the interplay of multiple developments at three analytical levels: niches (the locus for radical innovations), socio-technical regimes (the locus of established practices and associated rules), and an exogenous socio-technical landscape (Rip and Kemp, 1998; Geels, 2002, 2005). These 'levels' refer to heterogeneous configurations of increasing stability, which can be seen as a nested hierarchy with regimes being embedded within landscapes and niches existing inside or outside regimes (Fig. 1).

The MLP helps explain why there may simultaneously be a flurry of change activities (at the niche level) and relative stability of existing regimes. The three analytical levels are briefly described below.

\subsection{Niches}

Within the MLP, novelties emerge in niches, which are "protected spaces' such as R\&D laboratories, subsidised demonstration projects, or small market niches where users have special demands and are willing to support emerging innovations (e.g. the military). Niche actors work on radical innovations that deviate from existing regimes. Niche-actors hope that their promising novelties are eventually used in the regime or even replace it. This is not easy, however, because the existing regime is stabilized by many lockin mechanisms. Nevertheless, niches are crucial for transitions, because they provide the seeds for systemic change.

The literature on niche-innovation (Kemp et al., 1998; Hoogma et al., 2002) distinguishes three social processes within niches:

- Learning processes on various dimensions; about imperfections of technology and how they may be overcome, issues of organisation, market demand, user behaviour, infrastructure requirements, policy instruments and symbolic meanings.

- The articulation (and adjustment) of expectations or visions, which on the one hand provide guidance and direction to the internal innovation activities, and on the other hand aim to attract attention and funding from external actors.

- The building of social networks and the enrolment of more actors, which expand the social and resource base of niche-innovations

Niches are often carried by experimental or demonstration projects, which allow niche actors to learn about innovations in reallife circumstances. Niches gain momentum if visions (and expectations) become more precise and more broadly accepted, if the alignment of various learning processes results in a stable configuration ('dominant design'), and if social networks become bigger (especially the participation of powerful actors may add legitimacy and bring more resources into niches). This latter mechanism has occurred with regard to alternative engine/motor technologies: 


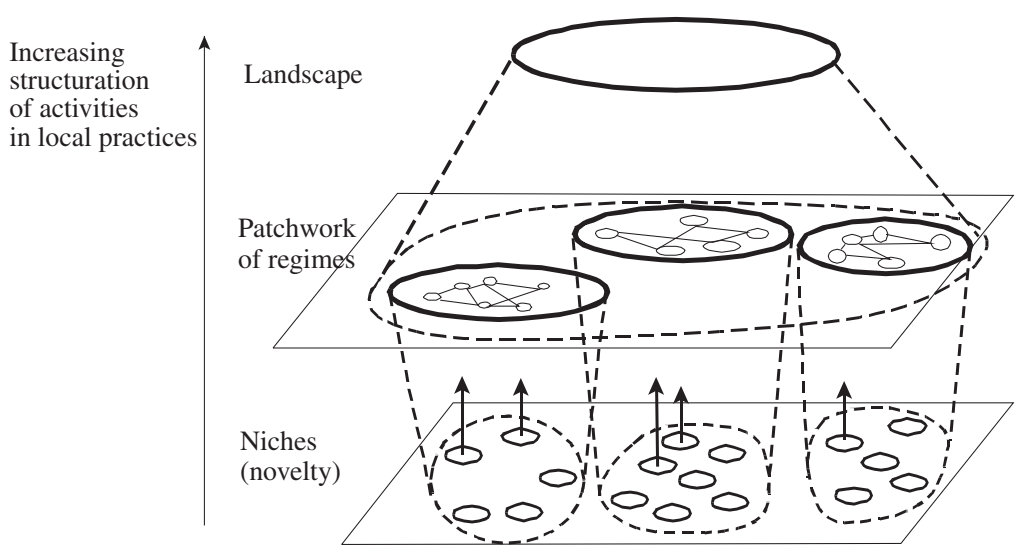

Fig. 1. Multiple levels as a nested hierarchy (Geels, 2002, p. 1261).

while fuel cells and battery-electric drive were initially pioneered by outsiders and start-ups, the big car manufacturers have moved into these areas, often creating strategic alliances with these small firms (or taking them over) (Dyerson and Pilkington, 2005).

\subsection{Socio-technical regime}

Novelties must compete with technologies that benefit from well-developed systems around them. The alignment of existing technologies, regulations, user patterns, infrastructures, and cultural discourses results in socio-technical systems (Geels, 2004). The system elements are reproduced, maintained and changed by various social groups and actors. These actors do not act in a vacuum, but are instead embedded in socio-technical regimes, which are the deep-structural rules that coordinate and guide actor's perceptions and actions (Giddens, 1984).

In existing regimes, innovation is mostly incremental because of lock-in mechanisms and path dependence. Change still occurs, but proceeds relatively predictably in certain directions, giving rise to stable trajectories. Examples of lock-in mechanisms are: shared beliefs that make actors blind for developments outside their scope, consumer lifestyles, regulations and laws that create market entry barriers, sunk investments in machines, people and infrastructure, resistance from vested interests, low costs because of economies of scale (Walker, 2000; Unruh, 2000).

The notion of socio-technical regimes encompasses not only firms and the activities of engineers, but also other social groups such as users, policy makers, special-interest groups and civil society actors. This concept thus helps overcome the tendency, which is prominent in innovation studies, to view manufacturers, such as the car industry, as the pivotal actors in regimes (such as automobility). Although car manufacturers are undoubtedly an important actor (who exert much influence through their product offerings, marketing strategies and political lobbying), automobility regimes are also sustained by habits of use, prevailing normality, and mindsets and established practices of professionals, such as transport planners, whose logic and choices help to reproduce a regime. The automobility regime is also sustained by everyday conversion and politics, and by cultural associations with freedom, modernity and individual identity (Urry, 2004).

In the transport domain there is not just one regime (automobility), but also other regimes (e.g. train, tram, bus, cycling). These transport modes have been around for many decades, are carried by specific communities of actors that have developed institutionalised practices, beliefs, capabilities etc. It makes no sense to call these transport modes 'niches' in the sense of being radically new and precarious innovations. But these transport modes capture only a small percentage of total mobility (in terms of passenger kilometres), and in that sense occupy small market niches. These transport modes can be called subaltern regimes in contrast to the dominant auto-mobility regime.

The notion of a regime introduces a structuralist element in the analysis, by assuming that actor behaviour is constrained by rules located at the collective level of a regime, which cannot easily be changed at the micro-level of individual action (Rip and Kemp, 1998). It is important to emphasise that 'regime' is an interpretive analytical concept, which invites the analyst to investigate the 'deep structure' behind activities, e.g. shared beliefs, norms, standardised ways of doing things, heuristics, and rules of thumb. While the notion of socio-technical 'system' refers to tangible and measurable elements (such as artefacts, market shares, infrastructure, regulations, consumption patterns, public opinion), the notion of 'regimes' refer to more intangible rules on which actors draw in concrete actions.

\subsection{Socio-technical landscape}

The sociotechnical landscape is the wider context, which influences niche and regime dynamics. It is a landscape in the literal sense, something around us that we can travel through; and in a metaphorical sense, something that we are part of, that sustains us (Rip and Kemp, 1998, p. 334). It includes spatial structures (e.g. urban layouts), political ideologies, societal values, beliefs, concerns, the media landscape and macro-economic trends. The socio-technical landscape represents the greatest degree of structuration in the sense of being beyond the control of individual actors.

\subsection{Temporal multi-level dynamics}

Fig. 2 provides an ideal-typical representation of how the three levels interact dynamically in the unfolding of socio-technical transitions. Although each transition is unique, the general dynamic is that transitions come about through the interaction between processes at different levels: (a) niche-innovations build up internal momentum, (b) changes at the landscape level create pressure on the regime, and (c) destabilisation of the regime creates windows of opportunity for niche-innovations. ${ }^{1}$ An important implica-

\footnotetext{
${ }^{1}$ Geels and Schot (2007) differentiated the basic model, and distinguished four types of transition pathways: (1) technological substitution, in which nicheinnovations emerge and replace existing regimes, (2) reconfiguration, in which niche-innovations are adopted into the existing system/regime, and subsequently lead to changes in the system architecture, (3) transformation, in which incumbent actors change regime elements (beliefs, search heuristics, investment patterns, regulations etc.) to solve problems and accommodate external pressures, and (4) dealignment and re-alignment, in which strong landscape changes lead to regime breakdown (de-alignment), followed by a prolonged period of niche-experimentation with multiple novelties, and gradual re-alignment around a 'winner'.
} 


\section{Increasing structuration of activities in local practices}

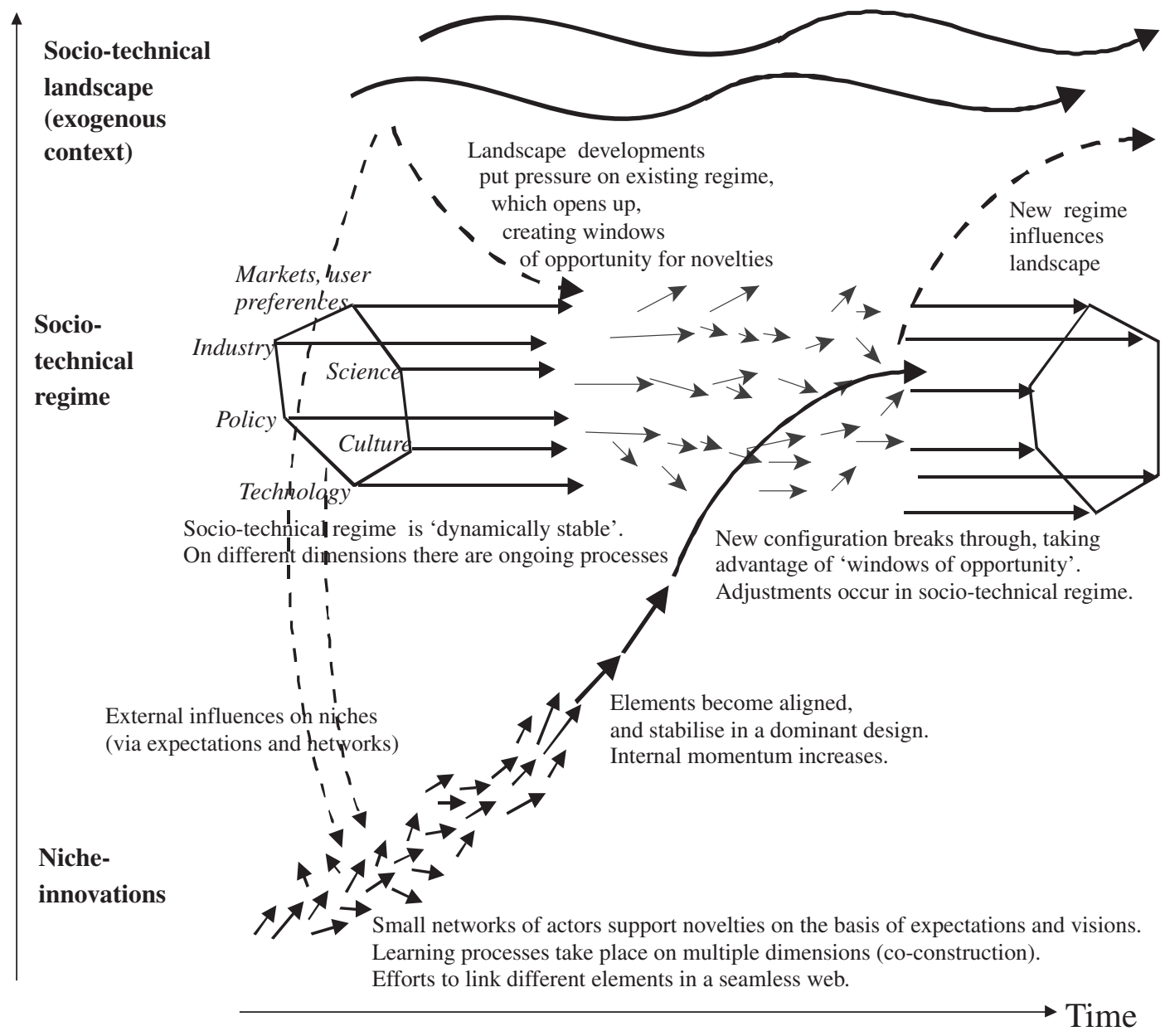

Fig. 2. Multi-level perspective on transitions (adapted from Geels, 2002, p. 1263).

tion is that the MLP does away with simple causality in transitions. There is no single 'cause' or driver. Instead, there are processes on multiple dimensions and at different levels which link up and reinforce each other ('circular causality'). Scholars who study transitions therefore emphasise lateral alignments, unexpected linkages, thresholds and tipping points.

The MLP is shot through with agency, because the trajectories and multi-level alignments are always enacted by social groups. There is no guarantee that transitions succeed: niche-innovations may fail to build up sufficient momentum or suffer setbacks; or tensions in existing regimes may remain small so that 'windows of opportunity' for niche-innovations do not materialise.

The MLP differs from the economic models, engineering approaches and psychological studies that pervade transport studies. Rather than focusing on technology fix or behaviour change, the MLP has the following characteristics: (a) Co-evolutionary and 'systemic' approach. Transitions are not driven by single factors (such as prices or technological change), but involve co-evolutionary developments between multiple dimensions (technology, industry, markets, consumer behaviour, policy, infrastructure, spatial arrangements and cultural meaning). (b) Actor-based approach. The MLP focuses on strategies, perceptions, actions and interactions between car drivers, transport planners, car manufacturing firms, and public opinion. (c) Stability and change. The MLP encompasses stability, lock-in and resistance to change on the one hand, and (seeds for) radical (systemic) change on the other hand. (d) Complex dynamics. The MLP does not employ linear causeand-effect relationships or simple drivers. Instead, it emphasises mutually reinforcing developments, alignments, co-evolution, innovation cascades, knock-on effects, and hype-disappointment cycles.

Because of these characteristics, the MLP is not a 'truth machine' that automatically produces the 'right' answers when the analyst enters the data. Instead it is a heuristic framework that guides the analyst's attention to relevant questions and issues. Application therefore requires both substantive knowledge of the empirical domain and theoretical sensitivity (and interpretive creativity) that help the analyst 'see' interesting patterns and mechanisms. The MLP represents a certain epistemological style (interpretive research), which is well suited to study uncertain and messy processes such as transitions.

While the MLP has a strong temporal orientation (explaining processes over time), it is fair to say that the spatial dimension has been less elaborated (although niche-projects often refer to local initiatives). For the transport domain this creates some complications. Although many dimensions of the automobility regime are national or international (e.g. highway infrastructure, traffic regulations, fuel taxes, mobility culture, engineering and transport planning expertise), some dimensions are local, e.g. parking fees, 
road maintenance, local policing, congestion charging, urban planning, and access to city centres. Subaltern regimes such as bus, light rail and cycling also have strong local dimensions (e.g. subsidies, concessions, right of way, special bus or cycle lanes). So, within national mobility regimes there can be local variations, especially at the urban level, that create deviation from the mainstream. Local actors may also support more radical niche-projects that can form the seeds for future transitions. This spatial dimension of transitions needs to be further elaborated in future work (see Hodson and Marvin, 2010; Bulkeley et al., 2011). The empirical sections below only briefly address this dimension.

\section{Applying the MLP to low-carbon transitions in transport}

This section uses the MLP to make an assessment of drivers and barriers for a transition towards low-carbon transport systems. This assessment, which is brief because of space constraints, draws on empirical discussions in a new book which investigates this topic for the UK and the Netherlands (Geels et al., 2012).

\subsection{Promising niche developments}

Over the last decade or so, various 'green' niches have emerged, carried by a range of experiments and demonstration projects. These innovative practices deviate in one or more dimensions (e.g. technical, cultural, behavioural, policy, infrastructure) from the established regime(s). Niches are characterised by uncertainty, because innovative practices have not yet resulted in best practices, rules of thumb, and stable routines. In that sense, niches differ from subaltern regimes (associated with bus, train, tram, and bicycles). Niche-innovations that are supported by more actors and receive more resources have higher degrees of momentum. I discuss six niche-innovations with different primary contributions to low-carbon transitions (Table 1 ). The first four niche-innovations are often carried by local initiatives with substantial roles for urban actors. Some cities have been particularly active in supporting one or more of these niches, e.g. Curitiba, Bogotá, Munich, Freiburg, Zurich, Paris, London, Manchester, Oxford, Singapore, Gothenburg, Amsterdam, Groningen, Copenhagen and Portland. But on a global scale, Banister (2011, p. 544) concludes that "the empirical evidence may be limited" that cities are moving towards a sustainable mobility paradigm. The considerable potential for reducing the energy (carbon) use in cities is not (yet) exploited because of a "lack of clear vision and the seductiveness of following the high mobility option" (Banister, 2011, p. 1544).

(1) Although inter-modal travel (use of several transport modes in one journey) has existed for a long time, the last decade saw a rise in schemes and projects aimed at facilitating and stimulating it, e.g. train-taxi schemes (cheaper taxi fares for passengers with train tickets, often on the condition that several passengers share one taxi), bus-rail integration schemes (bus services waiting for delayed trains), bike-rail integration schemes (bike carriages on trains, parking facilities, bike rental, or bike sharing schemes at train stations), car-public transport integration schemes (e.g. park-and-ride, transferia), intermodal ticketing schemes or smart-cards (passengers using one card for multiple transport modes), intermodal mobility services (company arranges entire travel package for business travellers). Most of these projects failed or remained small. Parkhurst et al. (2012) characterise intermodality as "a niche caught in a world of regimes". They found that: "Both rail and bus-related initiatives have generally remained piecemeal, tentative (with a number of trials ultimately ended) and over-dependent on local factors, such as the presence of policy entrepreneurs or particular coalitions of actors". The inter-modal niche remained small for various reasons: (a) time losses because of transfers; (b) support from regime players (railways, taxi companies, bus companies) has been lukewarm, because they see inter-modal travel as add-on activity, not as core business, and (c) "there is no powerful advocacy coalition speaking on behalf of intermodality and rarely are economic interests behind it". Parkhurst et al. (2012) conclude that "carrestraining policies are needed to complement investment in intermodal interchanges." Without those, the building of park-and-ride facilities may lead to an increase in car traffic.

(2) Certain cultural and socio-spatial niches deviate from 'normality' and challenge basic assumptions of the automobility regime. Some examples are: (a) sustainable urban planning, e.g. compact cities, smart growth, clustering of important destinations around public transport hubs, Transit Oriented Development, Complete Streets/Liveable Streets, (b) homezones which include soft edges, a staggered street axis, and visual narrowing of the space, (c) car sharing, and (d) public bike-sharing schemes. These practices are supported by social movement networks and community organisations which draw on counter-discourses that challenge the dominant order (e.g. sustainability, health, anticonsumerism). Although these practices have contributed to the emergence of a new discourse of 'sustainable mobility', Sheller (2012, p. 191) assesses that "it still remains questionable to what extent these cultural shifts will impact on the overwhelmingly automobile-centred pattern of majority mobility". The momentum of these niches is limited in terms of social networks, investment and public support. Some of them (e.g. liveable streets and homezones in the Netherlands) have existed for decades without much wider impact.

(3) New practices and initiatives have emerged in relation to mobility practices and demand management (relabelled in the UK as 'Smarter Choices'). Transport initiatives that aim to reduce car use include workplace and school travel plans, personalised travel planning, public transport information and marketing, travel awareness campaigns, residential and leisure travel plans, and urban cycling initiatives. Although positive predictions promise car use reductions by $10-20 \%$ (see Goodwin, 2012, for a review), these behavioural-change oriented initiatives are still in the early stages of development with fairly limited momentum. Their voluntary nature and zero costs makes them attractive to policy makers, but stand in the way of effectiveness, making them dependent on good intentions.

(4) Niche-innovations also transform subaltern regimes in public transport. There are attempts to modernise bus systems, e.g. through special bus lanes, real-time information panels, and short-distance radio systems that prioritize buses at traffic lights. Buses have also become a testing ground for green propulsion technologies, e.g. compressed natural gas, biofuels, battery-electric and fuel cells (often sponsored by national or European authorities). These innovations, which helped modernise public transport, are indicative of increasing political support in the last two decades (Harman et al., 2012). As a result, the decline in relative market shares of public transport modes in the 1980s and 1990s has been halted and turned into moderate growth in urban areas (e.g. light-rail systems and improved bus services) and for medium-long trips (e.g. high-speed railways). For low-density areas (outside cities and at the borders of cities) public transport tends to be expensive and generally unattractive. Still, it seems that improvements in public transport services 
Table 1

Overview of niche-innovations.

\begin{tabular}{|c|c|}
\hline Niche-innovations & Contribution to low-carbon transitions \\
\hline 1. Intermodal travel & New (integrated) modes of transport \\
\hline $\begin{array}{l}\text { 2. Cultural and socio-spatial } \\
\text { innovations }\end{array}$ & $\begin{array}{l}\text { Reduced travel distance, new } \\
\text { ownership styles }\end{array}$ \\
\hline 3. Demand management & $\begin{array}{l}\text { Reduced car use, behavioural/ } \\
\text { organisational change }\end{array}$ \\
\hline 4. Public transport innovations & Modal shift \\
\hline \multicolumn{2}{|l|}{$\begin{array}{l}\text { 5. Information and communication } \\
\text { technologies: }\end{array}$} \\
\hline $\begin{array}{l}\text { (a) Intelligent transportation } \\
\text { systems (ITS) }\end{array}$ & (a) Technical efficiency measures \\
\hline $\begin{array}{l}\text { (b) Tele-working, tele-shopping } \\
\text { etc. }\end{array}$ & $\begin{array}{l}\text { (b) Reducing travel needs } \\
\text { (substitution) }\end{array}$ \\
\hline 6. Green propulsion technologies & $\begin{array}{l}\text { More efficient fulfilment of existing } \\
\text { travel needs }\end{array}$ \\
\hline
\end{tabular}

are insufficient to convince car users to abandon their cars. A modal shift from cars to public transport would probably require a greater focus on spatial planning strategies and significant alterations to regulations and taxes.

(5) Information and Communication Technologies (ICTs) have given rise to two niches. The first niche, Intelligent Transportation Systems (ITS), is facilitated by the integration of ICT devices into transport and highway systems. ${ }^{2}$ ICT-devices are used to gather information, report accidents, control information panels and signs (speed signalling, highway dosage), and manage traffic flows (often from centralised control centres). The promise of the ITSniche is that 'cybercars' (vehicles enhanced with data processing, information transmission, and mobile communications capacities) and digitally enacted environments may enhance the efficiency of the transport system (i.e. improved traffic flows). ITS is embedded in an engineering logic and ITS-champions expect much from technological solutions (to facilitate better route planning, real-time travel information, automated vehicle guidance etc.). The ITS-niche has gathered momentum since the 1990s (Geels, 2007), and is actively supported by policy makers, highway engineers, transport planners, and traffic managers, because of the promise that ITS can help reduce congestion problems. Commercial interests (car industry, map digitisation industry, telecom providers) also support the niche because of its economic potential.

Secondly, the diffusion of ICT into everyday life may give rise to an information society with new practices such as tele-working, tele-shopping, tele-conferencing. While some of these practices may diminish the need for actual travel, others may generate new mobility needs (e.g. making new friends through cyberspace and then deciding to visit them). The relation between substitution effects and generation effects is an important debate in transport studies (Mokhtarian, 2002). ICT may also changes travel practices, because their integration into cars or public transport may bring fun and entertainment by enabling passengers to watch videos, use the (mobile) Internet, or communicate with the home or office. But Dennis and Urry (2009) warn that ICT may also lead to a 'darker' future such as a 'digital panopticon' with centralised planners using travel information for surveillance and control of people.

(6) Niches of green propulsion technology such as batteryelectric vehicles (BEV) and fuel-cell vehicles (FCV) have acquired substantial momentum in the last five or ten years.
Orsato et al. (2012) suggest that these niche developments are supported by: (a) $\mathrm{CO}_{2}$ regulations (in Europe) and government subsidies for R\&D programs and adoption, (b) new entrants such as Better Place, Chinese battery company BYD, and Ballard, which are fully committed to BEV and FCV (c) joint ventures between incumbent car companies and component suppliers, e.g. Toyota and Matsushita (a battery supplier), Nissan and NEC, and (d) electric utilities and local governments support BEV-projects. While BEV and FCV niches have gathered momentum, there are also some reasons for caution. In the last 20 years, green propulsion technologies have experienced several ups and downs (hypedisappointment cycles), which are summarised in Fig. 3.

There was much public attention for BEVs from 1990-1998, triggered by General Motor's innovation efforts with the Impact and the California zero-emission mandate. While the hype weakened in the late 1990s, there has been a revival in the last couple of years with renewed efforts (also from electric utilities, entrepreneurs, and governments) to develop and commercialise BEVs. From 1995 to 2005, there was much attention for fuel cells and hydrogen, related to serious innovation efforts from Daimler-Benz, visions about a hydrogen economy (Rifkin, 2002), and large scale government programs (US, EU). But the hype has declined in recent years, because of uncertainties about technical barriers (e.g. onboard hydrogen storage), costs, and infrastructure (Romm, 2005). From 2000 to 2005 there was a hype around biofuels, with promises of substantial sustainability benefits. In 2003 the European Biofuels Directive formulated ambitious goals of $2 \%$ biofuels in 2005 (which was not met $^{3}$ ), 5.75\% in 2010 and $10 \%$ in 2020. The biofuel hype diminished after 2005, because of concerns about sustainability effects and labour practices of biofuel production in developing countries (e.g. leading to deforestation and additional $\mathrm{CO}_{2}$ emissions). The food riots in 2007, which stimulated the discourse that biofuels compete with food production, caused a backlash which further damaged its public reputation. Nevertheless, increases in biofuel production, including in Brazil and the United States, indicate that public hype-cycles do not always affect techno-economic changes in a direct way. Hybrid-electric vehicles, commercialised in Japan in 1997, and in the United States and Europe in 2000 , created a new hype, especially when global car sales boomed after 2003. Although other car manufacturers initially derided Toyota for developing more complex and expensive cars, the unexpected success led to an innovation race, with other car manufacturers hurrying to develop their own hybrid models. HEVs also revived the interests in BEVs, because of possible crossovers between both technologies (e.g. via plug-in hybrids).

Although niche activities in the green propulsion area have increased substantially in the last five years, it remains difficult to predict which technology will win and how long this will take. Expectations about HEV and BEV have increased since 2005, but it is too early to write off hydrogen and fuel cells. Because car companies themselves also do not know which technology will win, most of them use portfolio strategies to prepare themselves for future strategic games, in case 'sustainability' or fuel economy gains further prominence. With regard to speed, it is likely that diffusion of green propulsion technologies will be slow, especially for BEV and FCV, which are both much more expensive than internal combustion engines, and require new or upgraded recharging/refuelling infrastructures. Although HEVs (hybrid-electric vehicles) do not require a new infrastructure, the fact that they cost a few thousand dollars more than petrol cars of equal size already hampers

\footnotetext{
2 These devices include video cameras, magnetic road detectors, computer networks, communication technologies, electronic signalling devices, navigation technologies (e.g. TomTom), and information devices.
}

${ }^{3}$ Biofuels made up about $1.4 \%$ of EU wide fuel in 2005 (http://www.bioenergywiki.net/European_Union). 


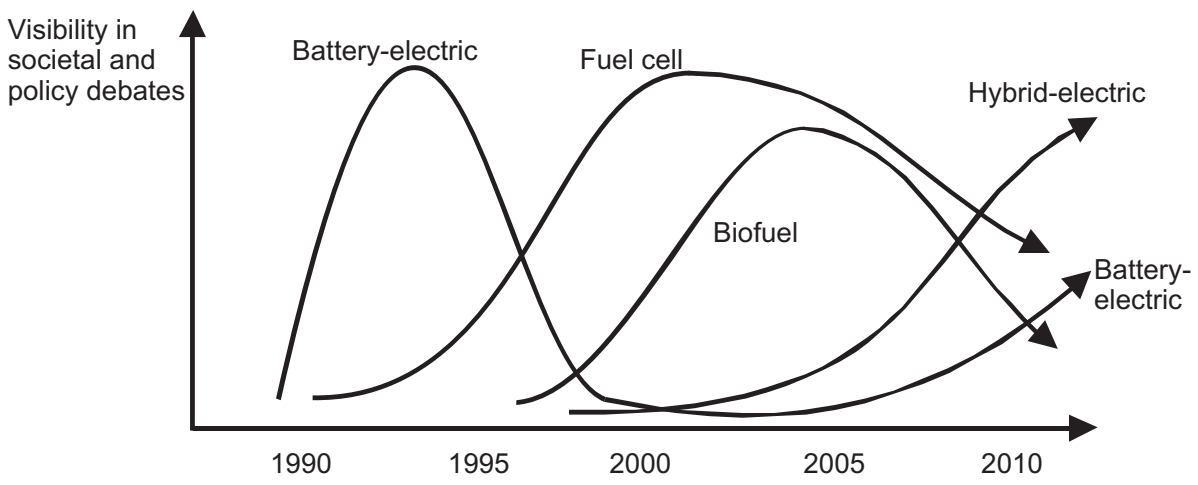

Fig. 3. Hype-disappointment cycles for green car propulsion technologies.

their diffusion beyond the movie stars or 'green minded' middle classes, which in most countries constitute only a few percent of the population.

Consequently, the diffusion of green cars will greatly depend on taxes or subsidies, tougher $\mathrm{CO}_{2}$ regulations, technical improvements, and public investments in infrastructure. Enhanced support measures for green cars, in turn, will depend on a cultural sense of urgency about climate change or higher fuel prices (perhaps due to Peak Oil), which create more pressure on policy makers. Although there is more talk about climate change than five years ago, this does not seem to be accompanied by a great sense of urgency, because people do not yet experience the (full) effects of climate change (or Peak Oil). Diffusion of green cars is also likely to be slow, because it takes time to replace large fleets of cars.

\subsection{Landscape developments}

The automobility regime faces both destabilizing and stabilizing landscape pressures. Destabilising landscape pressures come from:

(1) Discussions of climate change have led to public concerns and some policy action at the European level, e.g. subsidies for innovation programs and $\mathrm{CO}_{2}$ regulations for new cars. European regulation 443/2009 stipulates a fleet average target of 130 grams of $\mathrm{CO}_{2}$ per kilometre for new cars in $2015 .{ }^{4}$ This target, which will be reviewed in 2013, could be replaced with a tougher longer-term target of $95 \mathrm{~g} \mathrm{CO}_{2}$ per kilometre in 2020. While the first target can probably still be met with incremental innovations that stay within the current technical regime, the longer-term target will probably require more radical innovations, such as fuel cells, hybrids or battery-electric vehicles. While climate change has begun to be addressed at the European level, it is fair to say that local and national transport policy makers pay much less attention to climate change.

(2) Peak Oil, which refers to the peaking of maximum rates of conventional oil production, will be important for the automobility regime, because more than $95 \%$ of all cars run on petrol. There are many uncertainties, however, both with regard to the timing of peak production and the subsequent shape of oil production, which could either follow a bellshaped curve, with a rapid decline after the peak, or stay on a plateau for a prolonged period of time, because rising prices make difficult-to-get oil more economically feasible, because of enhanced innovation in oil recovery, or because of accelerated exploitation of unconventional oil. Although

\footnotetext{
4 Between 1995 and 2004 average emissions from new cars sold in the EU fell from $186 \mathrm{~g} \mathrm{CO}_{2} / \mathrm{km}$ to $163 \mathrm{~g} \mathrm{CO}_{2} / \mathrm{km}$. The European Commission introduced tougher $\mathrm{CO}_{2}$ regulations, because the industry seemed to be unable (or unwilling) to meet the voluntary target of $140 \mathrm{~g} / \mathrm{km}$ by 2008 .
}

Peak Oil does not mean that the world is quickly running out of oil, the price of oil and gasoline is likely to rise in coming decades, something that is likely to affect mobility behaviour (e.g. less car use, acquiring more fuel-efficient vehicles, finding a job closer to home or switching to alternative transport modes) or lead to stronger policy action with regard to renewable alternatives.

(3) The diffusion of ICT and the possible shift towards an information society with ubiquitous computing are pervasive landscape trends that have given rise to the ITS-niche and may transform daily life (giving rise to new practices such as tele-working, tele-shopping, tele-conferencing).

While the above landscape trends create pressure on automobility regimes, there are also societal characteristics and developments that help stabilize it. These include the following:

(1) A cultural preference for private property rather than collective ownership and use; this preferences stimulates the individual ownership of cars and works against car or bike sharing schemes.

(2) The cultural preference for speed and time saving stabilizes the car (which is often the fastest transport mode) and hinders public transport modes (Sachs, 1992). Many people actually like car driving, not just because it tends to be the fastest transport mode, but also because of feelings of autonomy and privacy (Sheller, 2004).

(3) The physical landscape (urban structures with a separation of work and home, roads) has been shaped around the car and stabilizes it.

(4) The car is stabilized by associations with cultural values such as freedom, choice, progress, wealth and status (Sachs, 1992).

(5) Macro-economic growth enables consumers in developing countries (China, India, Brazil) to buy their first car (Freund and Martin, 2000; Sperling and Gordon, 2009), while households in developed nations are moving towards multiple cars per household (see Fig. 4).

(6) The demand for mobility increases because globalisation and a shift towards a network society (Castells, 19961998 ) increase the flow of goods and people.

\subsection{Stability in the socio-technical regime ${ }^{5}$}

The automobility regime is not only stabilized by certain landscape trends, but also by lock-in mechanisms on various regime dimensions: (a) sunk investments in road, urban and spatial

\footnotetext{
5 This section is more general than the UK and Netherlands. Many industrialised (Western) countries share elements of the automobility regime (although there may be differences in style).
} 


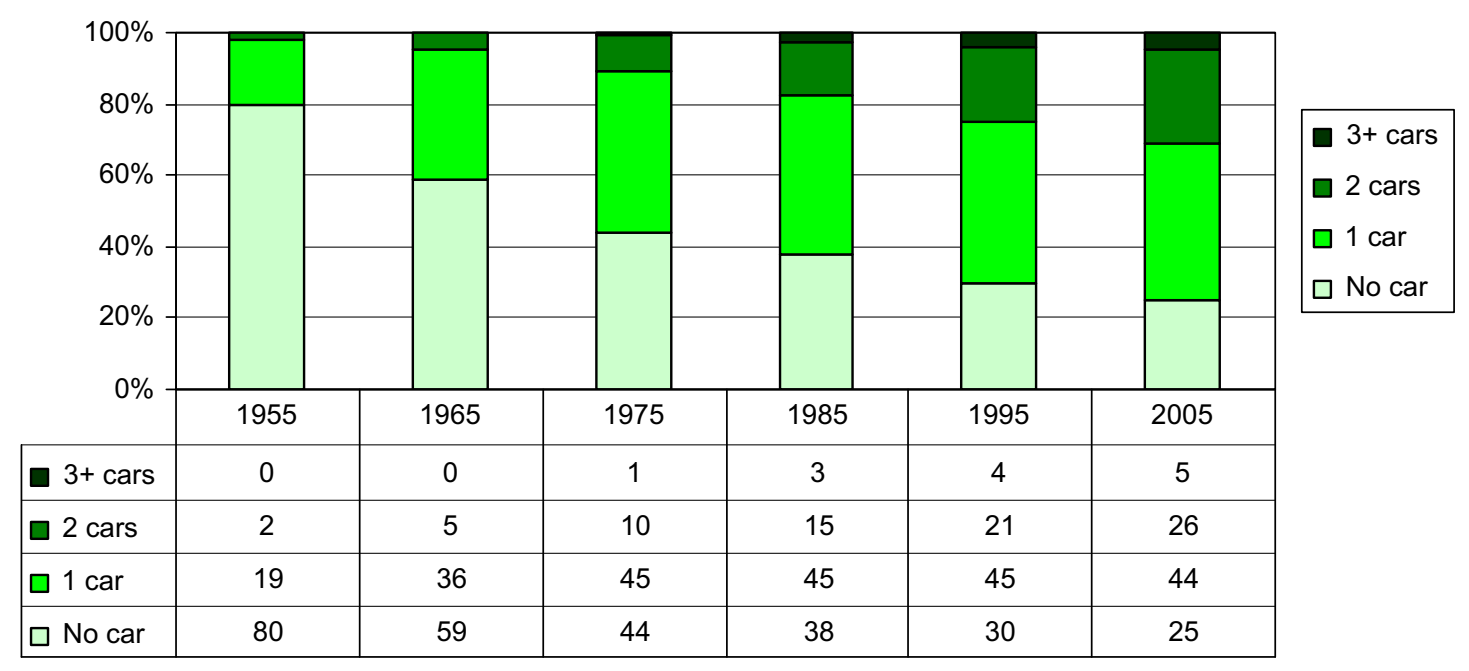

Fig. 4. Relative distribution (\%) of the number of cars in UK households (Department for Transport, 2008).

infrastructures, (b) sunk investments in plants, skills, and people, which create vested interests for industry actors, (c) user patterns and life styles, which provide social embeddedness of the car, (d) consumer preferences that benefit cars, e.g. convenience, speed, relative cost (many people actually like cars, which on many performance dimensions score better than other transport modes); (e) cultural values and positive discourses around the 'Joy of driving' and 'Love affair with the car'; (f) vested interests (industry, car lobby, road lobby) that resist major change, and ( $\mathrm{g}$ ) beliefs from established actors (e.g. transport planners, policy makers, industry actors) that take existing practices for granted and legitimate the status quo. These lock-in mechanisms stabilize the existing regime, leading incumbent actors to prefer incremental changes that stay within the bounds of the existing regime.

Another reason that most incumbent actors do not actively work towards (radical) low-carbon transitions is that climate change is not at the top of their problem rankings. Limiting the assessment to three social groups (industry, policy, and consumers), I suggest that other problems are given more priority.

- For the car industry it seems that survival in cut-throat competition and under-utilisation of factories and cost pressures are the two main problems, which lead them to focus on cost-savings, e.g. through mergers and attempts to improve production efficiency (factory innovation and reorganisation) (Orsato and Wells, 2007). Thirdly, market saturation in developed countries leads firms to focus on selling cars in emerging economies. The fourth issue is competition through product innovation, which translates into technical innovation oriented towards higher engine performance, more ICT in cars, more safety devices. Environmental sustainability pressures rank perhaps fifth on the industry's problem hierarchy, mainly because of government regulations, and to a lesser degree because of consumer demand (Wells, 2010). Because of these pressures, the industry is developing 'greener' cars such as HEV, FCV, BEV and biofuels. But at present, these green technologies are mainly a hedging or reputation strategy (Sperling and Gordon, 2009). The industry's main strategy is still the improvement of the internal combustion engine (ICE), with innovations such as variable valve timing and direct fuel injection systems. On average, around $80 \%$ of the industry's patents were awarded to ICE-related technology, against only about $20 \%$ for technologies associated with pure battery EVs and Hybrid EVs (Oltra and St. Jean, 2009).
- For national and local policy makers, I suggest the following ranking of priorities in transport policy: (1) stimulate the economy by facilitating the smooth flow of goods and people, (2) ensure social equity by facilitating access to mobility for disadvantaged groups (especially via public transport), and (3) addressing negative externalities in the following order of importance: (a) congestion, because it has negative social and economic implications, (b) local 'quality of life' problems such as air pollution, parking and spatial problems, (c) safety (traffic deaths and injuries), and (d) environmental sustainability such as climate change. This externality ranking explains why most transport policy programs address congestion (via congestion charging, dynamic traffic management, and demand management). Environmental sustainability is less prominent in transport policies at the national and local levels: symbolic actions and debates are limitedly translated into effective policies. European policy makers are more active in this regard (e.g. with $\mathrm{CO}_{2}$ regulations discussed above).

- While 'people as citizens' express concerns about climate change, this differs from the priorities of 'people as consumers and car drivers'. Consumer surveys suggest that people apply the following criteria when they buy a new car: (1) most important: vehicle price, car size, reliability, comfort, safety, running costs, fuel consumption, appearance, (2) medium importance: performance, power, image, brand name, insurance costs, and (3) least important: depreciation, sales packages, dealership, environmental issues, vehicle emissions, road tax, engine size, equipment (King Review, 2007, p. 60). So, car drivers appear to pay limited attention to environmental problems when buying a new car.

The implication of the above discussion is that the automobility regime still seems fairly stable in relation to sustainability and climate change problems. The reason for this assessment is not that the problems are small, but that important regime actors are neither fully committed (yet) to acknowledging these problems nor to placing them on agendas with a high sense of urgency. The car industry and automobile clubs are powerful advocates in defending the right to drive and fighting off taxes and other measures to limit car mobility. Their power lies in part in expressing a popular view. No powerful societal group is calling for the need for transformative change. Those who do are often marginalized. Amongst policy makers the need for radical change in the transport sector is not widely accepted. They are ambiguous about it, and so 
is the transport profession. ${ }^{6}$ Although some functional problems that directly affect transport systems (e.g. congestion, parking) are recognised and lead to more attention for ICT, dynamic traffic management and congestion charging, collective good problems and negative externalities (such as climate change) receive much less attention or are being downplayed.

\subsection{Cracks in the regime}

Although the automobility regime still has substantial stability, several cracks are appearing. These cracks suggest that the regime may not be as strong as it used to be, although it is still dominant compared to other transport modes.

One important crack relates to cities, where physical constraints and quality of life issues seem to lead (some) authorities to implement car restraining measures such as parking restrictions and tariffs, traffic calming schemes, and the creation of traffic-free pedestrianised centres, which challenge the ubiquity of cars in certain places. ${ }^{7}$ Because (some) cities also play an active role in stimulating bus lanes, bicycles and road pricing, they can be seen as a new actor that challenges the established regime in some respects.

A second crack is that growth of car mobility (in terms of passenger miles), which was fast in the post-war decades, seems to have come to a halt in developed countries such as the UK, where it actually declined somewhat (Figs. 5 and 6). ${ }^{8}$ This development suggests that we could be entering a period in which attention shifts from the expansion of the car-based system to its transformation to address the various problems and externalities.

A third crack is some weakening in the commitment of policy makers to the auto-mobility regime. In the 1990s, UK transport policy changed from the 'predict-and-provide paradigm', which had been dominant since the 1960s, to include new principles such as such as demand management, traffic management and 'sustainable mobility' (Owens, 1995). ${ }^{9}$ Whereas predict-and-provide signalled policy commitment to automobility expansion, the new principles suggest that policy makers have become more critical about the building of more roads. This did not mean, however, that policy makers discontinued investment in road expansion (when this was deemed necessary). Their willingness to bail out the car industry during the financial crisis (with direct subsidies and demand stimulus policies such as cash for clunkers) also suggests that policy commitment to cars is still substantial. ${ }^{10}$

A fourth crack is that regime actors (especially policy makers, transport planners, and the car industry) are aware of environmental limits and landscape pressures such as climate change and Peak Oil. Car companies, for instance, are not impervious to ideas such as sustainable mobility, but they understand this primarily as an issue of greener cars and not as a comprehensive change in transport systems (e.g. intermodal traffic, car sharing etc.).

\section{Conclusions and policy suggestions}

Based on the above MLP analysis I conclude that: (a) the automobility regime is still dominant and stable, although less so than

\footnotetext{
${ }^{6}$ Banister (2011, p. 1545), for instance, suggests that: "At present the scale and nature of the changes necessary in the transport sector to address climate change have not been seriously debated".

7 Some Dutch cities already introduced homezones in the 1970s and pedestrianised city centres in the 1980s (Schwanen et al., 2004).

${ }^{8}$ Millard-Ball and Schipper (2011) suggest this is a more general trend in several industrialised countries.

${ }^{9}$ In the Netherlands, this shift occurred in the mid-1980s, and prepared the ground for the Second Structural Plan for Traffic and Transport (1988).

10 While these rescue efforts suggest that governments take great interest in healthy car industries, the political capital of the latter may have weakened, so that interventions may play out differently in future.
}

fifteen years ago, (b) there are some (moderate) cracks in the regime, (c) most of the promising niches have limited internal momentum; and (d) this momentum is larger, however, for the technical niches of green propulsion technology and ICT/ITS, which are therefore better placed to take advantage of the emerging windows of opportunity. This analysis suggests that we are only in the early phases of a low-carbon transition in the transport domain. The main drivers for this transition are: (a) public concerns about Peak Oil and climate change, (b) government policies $\left(\mathrm{CO}_{2}\right.$ regulations, innovation programs) aimed at the 'greening' of cars, and (c) car industry innovation strategies (with regard to BEV, HEV, FCV). But these drivers are not yet very strong, whereas the mechanisms of inertia and stability are still substantial. The hype-cycles in the green propulsion niche make it difficult to predict which technology will win. It can also be doubted if these green technologies will be able to deliver the major cuts in $\mathrm{CO}_{2}$ emissions needed to address climate change (Chapman, 2007; Banister, 2008). The ITS niche is likely to expand, because it is pushed by powerful companies and embraced by transport professionals. While ITSchampions promise efficiency improvements of the existing transport system, it remains to be seen if ITS-innovations form structural solutions or temporary measures that delay gridlock for another 10 years or so. ICT also facilitates congestion charging and road pricing, which may transform roads from public goods into payable services. Public acceptance and political will are the greatest uncertainties for this development. ${ }^{11}$

Alternative transition paths are possible in principle. The niches of intermodal transport, demand management, sustainable urban planning, car and bike-sharing offer possibilities for more radical and systemic change with potentially greater sustainability benefits (Banister, 2008). But realisation of these transition paths would require several changes in actor attitudes and strategies: a willingness of national governments to introduce car-restraining policies, a stronger role of local and city governments, stronger innovation strategies by public transport actors, and a willingness of consumers to change mobility routines and use cars less. At present, there are not many indications of these kinds of changes. Because these alternative transition paths entail changes in mobility routines and a reconfiguration of urban physical urban structures, they would also be slow to unfold (e.g. after 2030).

For the next 20 years it therefore seems likely that the carbased transport system remains dominant (although maybe somewhat less in relative terms); that public transport modes (train, bus, light rail) experience some further growth; and that we see a gradual greening of technology. In terms of the theoretical transition pathways discussed above (footnote 1 ), this projection correlates with the reconfiguration path, in which regime actors survive by adopting technical niche-innovations. The analysis of dominant actor orientations and strategies suggest that inter-modal transport, cultural and socio-spatial changes, and demand management practices remain small niches, supported by urban actors and social movements that are willing to deviate from mainstream trends. The continuation of these alternative niches is important, because they provide seeds for more radical change in case the other transition path appears unable to address increasing sustainability problems.

Following the MLP-logic, transition policy should follow a twopronged strategy: (a) stimulate the emergence and diffusion of niche-innovations, and (b) enhance selection pressure on the regime through economic instruments (e.g., carbon taxes, emission trading, road pricing) and regulation (e.g., environmental legislation). My assessment is that transport policies give moderate

\footnotetext{
11 Manchester and Edinburgh rejected congestion charging in referendums (in 2008 and 2005), while Dutch plans to introduce road pricing on highways kept being postponed and delayed during the 2000s.
} 


\section{Annual Travel Per Person GB}

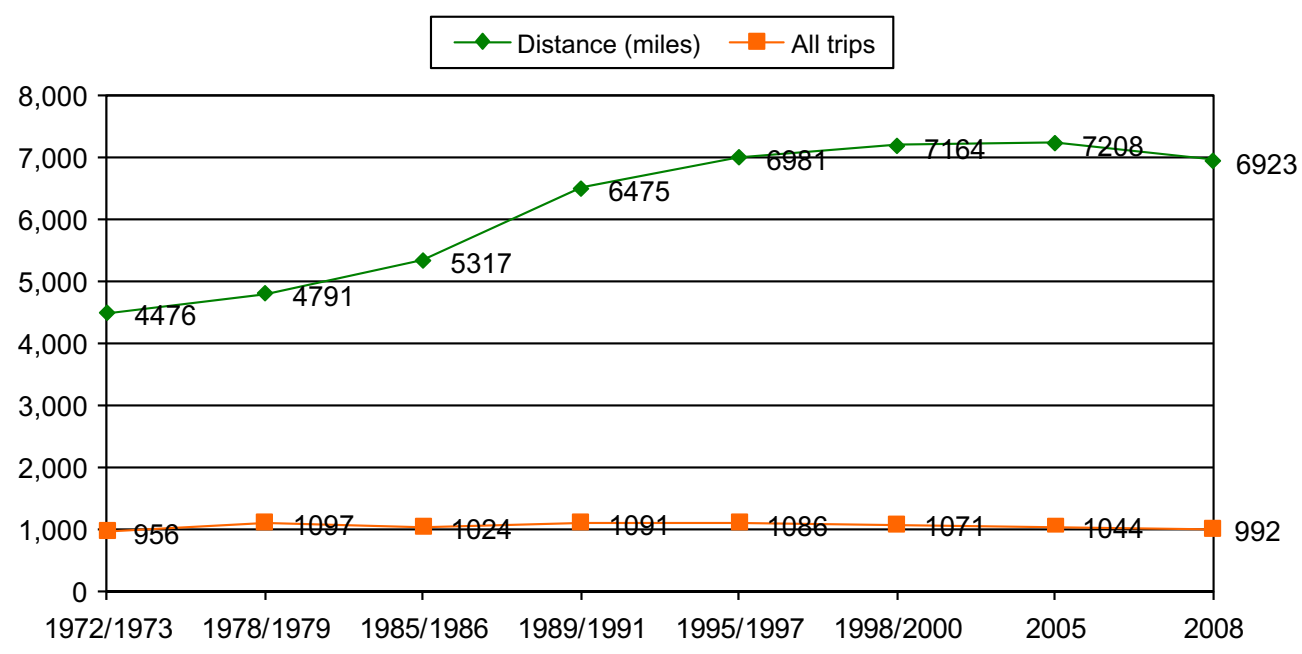

Fig. 5. Mobility trend in Great Britain (Department for Transport, 2008).

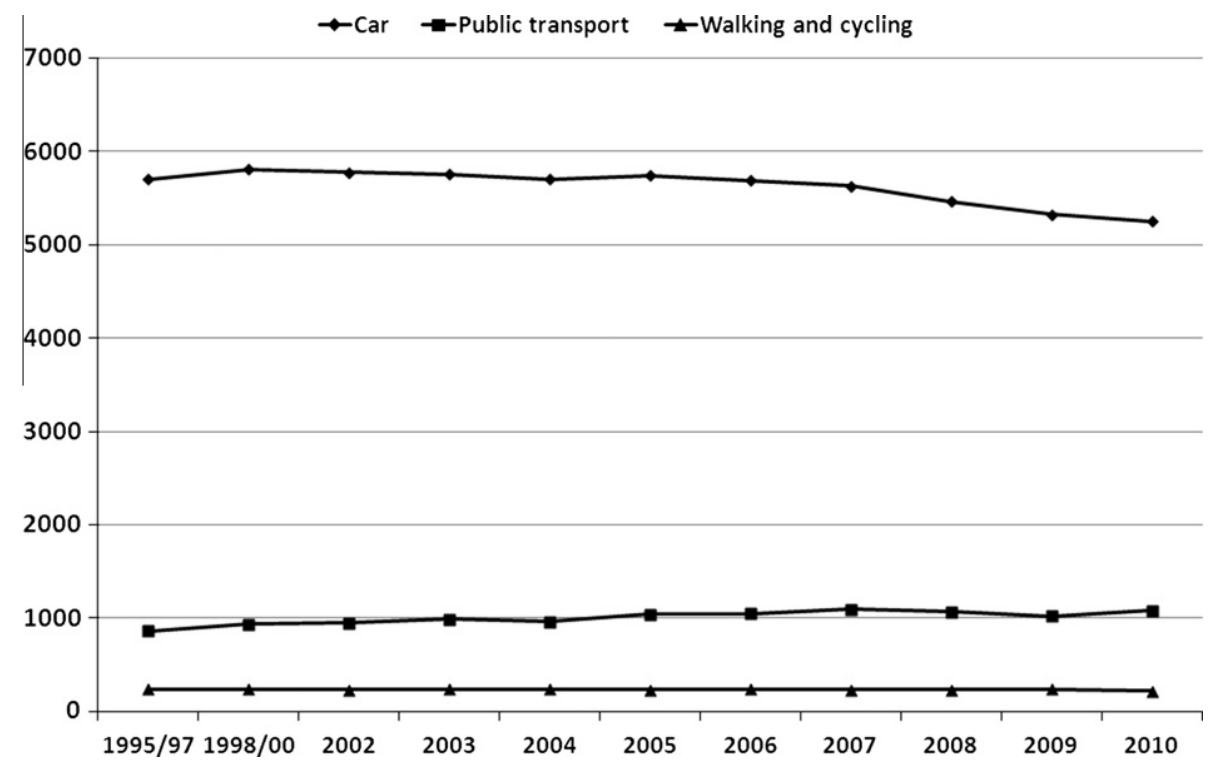

Fig. 6. Average distance (in miles) travelled per person per year in Great Britain (Department for Transport, 2011).

attention to the first and little attention to the second strategy. Although transport planners and policymakers pin their hopes on technical solutions (rather than on facilitating broader transformative change), they are not driving this agenda forcefully. In most countries, transport innovation policy is rather piecemeal, both in financial terms and coordination. I therefore agree with Sperling and Gordon (2009) that low-carbon transitions require stronger innovation policies: "If alternatives are to take root, we need (...) vastly expanded science and technology research, development, demonstration, and investment, along with consistent, powerful government policies that encourage these investments" (p. 110). The second strategy (restraining and reducing car traffic) receives even less attention, because it is not very popular with the electorate and business interests. Although some cities implement policies that restrain cars and encourage alternatives to cars, often for reasons of urban regeneration and quality of life, this remains a somewhat isolated instance of creating pressure on the automobility regime.

In sum, it appears that transport policies are currently only weakly oriented towards low-carbon transitions. Transport policies are driven by other considerations, because policy makers are constrained by two dependencies. First, policy makers are constrained by the wider public, who form the electorate they (are supposed to) represent. Policy makers seem to follow rather than lead public opinion. If they introduce tough policies, they risk electoral defeat or public protest. ${ }^{12}$ In general, governments tend to facilitate car mobility, because the car is culturally accepted and embedded in people's lives. Secondly, policy makers are dependent on industries for jobs, taxes, economic growth and new technologies (Luger, 2000). This dependence makes governments receptive to industry wishes, even when the public good is at stake. With regard to $\mathrm{CO}_{2}$ regulations, policy makers seem to follow what is technologically feasible, relying on industry assessments about this (Wells, 2010). The car industry thus has substantial power to influence the strictness of regulations. These dependencies explain why it is difficult for policy makers to introduce tough regulations or

\footnotetext{
12 In the UK, fuel protests in 2000 led to an institutionalised fear not to go against what the public wants, and to postponement of ambitious transport policies formulated in the 1990s.
} 
car-restraining policies. Policy makers have no privileged position outside the system (a 'cockpit') from which they can pull levers and change the transport system. Instead, they are part of the system and are constrained by their dependence on other actors. This dependence has become stronger with macro-trends such as liberalisation, privatisation, deregulation, and devolution (Docherty and Shaw, 2011).

This discussion highlights the importance of analysing the interactions between industry, policymakers, consumers, and civil society. In that sense I agree with Banister's (2008, p. 79) call for the "need to understand behaviour [of all stakeholders], and to explore the means by which cooperation and support can be obtained, so that real change can take place". The socio-technical approach and multi-level perspective were developed to analyse the role of these multi-actor processes in transitions. This article has aimed to show that the MLP can be used for making comprehensive analyses of the possibilities, barriers and drivers of transitions towards sustainable transport. It is hoped that transport studies scholars find some of these ideas useful to address multi-dimensional phenomena such as low-carbon transitions. Although the empirical assessments focused on the Netherlands and the United Kingdom, the conceptual framework can also be applied to other geographical jurisdictions. It is hoped that scholars with in-depth knowledge of transport systems, actors and contexts in other countries may use this perspective to make similar comprehensive assessments of low-carbon transitions in other parts of the world.

\section{Acknowledgements}

I want to thank two anonymous reviewers and Tim Schwanen for their useful comments on previous versions of the paper. This work has been supported by an ERC Grant (No. 204246).

\section{References}

Banister, D., 2008. The sustainable mobility paradigm. Transport Policy 15(1), 73-80. Banister, D., 2011. Cities, mobility and climate change. Journal of Transport Geography 19 (6), 1538-1546.

Bulkeley, H., Broto, V.C., Hodson, M., Marvin, S. (Eds.), 2011. Cities and Low Carbon Transitions. Routledge, New York

Castells, M., 1996-1998. The Information Age: Economy, Society and Culture, vol. 3. Blackwell, Cambridge, MA, Oxford.

Chapman, L., 2007. Transport and climate change: a review. Journal of Transport Geography 15 (5), 354-367.

Dennis, K., Urry, J., 2009. After the Car. Polity Press, Cambridge.

Department for Transport, 2008. Transport Statistics Great Britain, London.

Department for Transport, 2011. National Travel Survey. Department for Transport, London. <http://www.dft.gov.uk/pgr/statistics/datatablespublications/nts/> (accessed 19.03.11).

Docherty, I., Shaw, J., 2011. The transformation of transport policy in Great Britain? The new realism and new labour's decade of displacement activity. Environment and Planning A 43 (1), 224-251.

Dyerson, R., Pilkington, A., 2005. Gales of creative destruction and the opportunistic incumbent: the case of electric vehicles in California. Technology Analysis \& Strategic Management 17 (4), 391-408.

Elzen, B., Geels, F.W., Green, K. (Eds.), 2004. System Innovation and the Transition to Sustainability: Theory, Evidence and Policy. Edward Elgar, Cheltenham.

Freund, P., Martin, G., 2000. Driving South: the globalization of auto consumption and its social organization of space. Capitalism Nature Socialism 11 (4), 51-71.

Geels, F.W., 2002. Technological transitions as evolutionary reconfiguration processes: a multi-level perspective and a case-study. Research Policy 31 (89), 1257-1274.

Geels, F.W., 2004. From sectoral systems of innovation to socio-technical systems: insights about dynamics and change from sociology and institutional theory. Research Policy 33 (6-7), 897-920.

Geels, F.W., 2005. The dynamics of transitions in socio-technical systems: a multilevel analysis of the transition pathway from horse-drawn carriages to automobiles (1860-1930). Technology Analysis \& Strategic Management 17 (4), 445-476.

Geels, F.W., 2007. Transformations of large technical systems: a multi-level analysis of the Dutch highway system (1950-2000). Science Technology \& Human Values 32 (2), 123-149.

Geels, F.W., Schot, J.W., 2007. Typology of sociotechnical transition pathways. Research Policy 36 (3), 399-417.

Geels, F.W., Kemp, R., Dudley, G., Lyons, G. (Eds.), 2012. Automobility in Transition? A Socio-Technical Analysis of Sustainable Transport. Routledge, New York
Giddens, A., 1984. The Constitution of Society: Outline of the Theory of Structuration, Berkeley [etc.]. University of California Press.

Goodwin, P., 2012. Providing road capacity for automobility: the continuing transition. In: Geels, F.W., Kemp, R., Dudley, G., Lyons, G. (Eds.), Automobility in Transition? A Socio-Technical Analysis of Sustainable Transport. Routledge, New York, pp. 140-159.

Harman, R., Veeneman, W., Harman, P., 2012. Innovation in public transport. In: Geels, F.W., Kemp, R., Dudley, G., Lyons, G. (Eds.), Automobility in Transition? A Socio-Technical Analysis of Sustainable Transport. Routledge, New York, pp. 286-307.

Hodson, M., Marvin, S., 2010. Can cities shape socio-technical transitions and how would we know if they were? Research Policy 39 (4), 477-478.

Hoogma, R., Kemp, R., Schot, J., Truffer, B., 2002. Experimenting for sustainable transport: the approach of strategic niche management. Spon Press, London, New York.

Huber, J., 2000. Towards industrial ecology: sustainable development as a concept of ecological modernization. Journal of Environmental Policy \& Planning 2 (4), 269-285.

Kaiser, F.G., Ranney, M. Hartig, T., Bowler, P.A., 1999. Ecological behavior, environmental attitude, and feelings of responsibility for the environment. European Psychologist 4 (1), 59-74.

Kemp, R., Schot, J., Hoogma, R., 1998. Regime shifts to sustainability through processes of niche formation: the approach of strategic niche management Technology Analysis and Strategic Management 10 (2), 175-196.

King, J., 2007. The King Review of Low-Carbon Cars. H.M. Treasury, United Kingdom.

Luger, S., 2000. Corporate Power, American Democracy, and the Automobile Industry. Cambridge University Press, Cambridge.

Millard-Ball, A., Schipper, L., 2011. Are we reaching peak travel? Trends in passenger transport in eight industrialized countries. Transport Reviews 31 (3), 357-378.

Mokhtarian, P.L., 2002. Telecommunications and travel: the case for complementarity. Journal of Industrial Ecology 6 (2), 43-57.

Næs, A., 1973. The shallow and the deep, long-range ecology movement. Inquiry $16,95-100$.

Newell, P., 2008. The political economy of global environmental governance. Review of International Studies 34 (3), 507-529.

Nykvist, B., Whitmarsh, L., 2008. A multi-level analysis of sustainable mobility transitions: niche developments in the UK and Sweden. Technological Forecasting and Social Change 75 (9), 1373-1387.

Oltra, V., Saint Jean, M., 2009. Variety of technological trajectories in low emission vehicles (LEVs): a patent data analysis. Journal of Cleaner Production 17 (2), 201-213.

Orsato, R.J., Wells, P., 2007. 'U-turn: the rise and demise of the automobile industry. Journal of Cleaner Production 15 (11-12), 994-1006.

Orsato, R., Dijk, M., Kemp, R., Yarime, M., 2012. The electrification of automobility: the bumpy ride of electric vehicles toward regime transition. In: Geels, F.W., Kemp, R., Dudley, G., Lyons, G. (Eds.), Automobility in Transition? A SocioTechnical Analysis of Sustainable Transport. Routledge, New York, pp. 205-228.

Owens, S., 1995. From 'predict and provide' to 'predict and prevent'? Pricing and planning in transport policy. Transport policy 2 (1), 43-49.

Parkhurst, G., Kemp, R., Dijk, M., Sherwin, H., 2012. Intermodal personal mobility: a niche caught between two regimes. In: Geels, F.W., Kemp, R., Dudley, G., Lyons, G. (Eds.), Automobility in Transition? A Socio-Technical Analysis of Sustainable Transport. Routledge, New York, pp. 308-334.

Pangbourne, K., Anable, J., 2011. Alternative travel futures: guest editorial. Journal of Transport Geography 19 (6), 1535-1537.

Rifkin, J., 2002. The Hydrogen Economy: The Creation of the Worldwide Energy Web and the Redistribution of Power on Earth. Tarcher/Putnam, New York.

Rip, A., Kemp, R., 1998. Technological change. In: Rayner, S., Malone, E.L. (Eds.), Human Choice and Climate Change, vol. 2. Battelle Press, Columbus, Ohio, pp. 327-399.

Romm, J.J., 2005. The Hype about Hydrogen: Fact and Fiction in the Race to Save the Climate. Island Press, Washington, DC.

Sachs, W., 1992. For Love of the Automobile: Looking Back into the History of Our Desires. University of California Press, Berkeley.

Schwanen, T., Dijst, M., Dieleman, F.M., 2004. Policies for urban form and their impact on travel: the Netherlands experience. Urban Studies 41 (3), 579-603.

Schwanen, T., Banister, D., Anable, J., 2011. Scientific research about climate change mitigation in transport: a critical review. Transportation Research Part A 45 (10), 993-1006.

Sheller, M., 2004. Automotive emotions: feeling the car. Theory, Culture \& Society $21,221-242$.

Sheller, M., 2012. The emergence of new cultures of mobility: stability, openings and prospects. In: Geels, F.W., Kemp, R., Dudley, G., Lyons, G. (Eds.), Automobility in Transition? A Socio-Technical Analysis of Sustainable Transport. Routledge, New York, pp. 180-202.

Smith, A., Stirling, A., Berkhout, F., 2005. The governance of sustainable sociotechnical transitions. Research Policy 34 (10), 1491-1510.

Smith, A., 2007. Translating sustainabilities between green niches and socio-technical regimes. Technology Analysis \& Strategic Management 19 (4), 427-450.

Sperling, D., Gordon, D., 2009. Two Billion Cars: Driving Towards Sustainability. Oxford University Press, New York.

Stern, N., 2006. Review on the Economics of Climate Change. H.M. Treasury, United Kingdom.

Unruh, G.C., 2000. Understanding carbon lock-in. Energy Policy 28 (12), 817-830.

Urry, J., 2004. The 'system' of automobility. Theory, Culture and Society 21 (4-5), 25-39. 
Urry, J., 2011. Climate Change and Society. Polity Press.

Van Driel, H., Schot, J.W., 2005. Radical innovation as a multi-level process: introducing floating grain elevators in the port of Rotterdam. Technology and Culture 46, 51-76.

Verbong, G.P.J., Geels, F.W., 2007. The ongoing energy transition: lessons from a socio-technical, multi-level analysis of the Dutch electricity system (19602004). Energy Policy 35 (2), 1025-1037.
Walker, W., 2000. Entrapment in large technology systems: institutional commitments and power relations. Research Policy 29 (7-8), 833-846.

Wells, P., 2010. The Automotive Industry in an Era of Eco-Austerity. Edward Elgar, Cheltenham. 